\title{
Performance or Marketing Benefits? The Case of
}

\section{LEED Certification}

\author{
Daniel C. Matisoff*1, Douglas S. Noonan ${ }^{2}$, Anna M. Mazzolini ${ }^{1}$ \\ ${ }^{1}$ Georgia Institute of Technology, 685 Cherry St NW, Atlanta, Georgia, 30332 \\ 2 Indiana University Purdue University, Indianapolis, 801 West Michigan Street, BS 3025 \\ Indianapolis, IN 46202
}

*Corresponding Author:

e-mail: Matisoff@gatech.edu

(T) 404-385-2623

(F) 404-285-0504

Keywords: Green Building; Green Signaling; Leadership in Energy and Environmental Design (LEED); Voluntary Environmental Policy; Voluntary Building Standards;

This is the author's manuscript of the article published in final edited form as: Matisoff, D. C., Noonan, D. S., \& Mazzolini, A. M. (2014). Performance or Marketing Benefits? The Case of LEED Certification. Environmental Science \& Technology, 48(3), 2001-2007.

http://doi.org/10.1021/es4042447 


\begin{abstract}
Green building adoption is driven by both performance-based benefits and marketing based benefits. Performance based benefits are those that improve performance or lower operating costs of the building or of building users. Marketing benefits stem from the consumer response to green certification. This study illustrates the relative importance of the marketing based benefits that accrue to Leadership in Energy and Environmental Design (LEED) buildings due to green signaling mechanisms, specifically related to the certification itself are identified. Of course, all participants in the LEED certification scheme seek marketing benefits. But even among LEED participants, the interest in green signaling is pronounced. The green signaling mechanism that occurs at the certification thresholds shifts building patterns from just below to just above the threshold level, and motivates builders to cluster buildings just above each threshold. Results are consistent across subsamples, though non-profit organizations appear to build greener buildings and engage in more green signaling than for-profit entities. Using nonparametric regression discontinuity, signaling across different building types is observed. Marketing benefits due to LEED certification drives organizations to build "greener" buildings by upgrading buildings at the thresholds to reach certification levels.
\end{abstract}




\section{Introduction}

Green building refers to the implementation of practices and products in construction that minimize harmful effects on the environment. With growing focus on sustainability, green building has been increasing in popularity, both on the commercial and residential levels.

Leadership in Energy and Environmental Design (LEED) certification is currently one of the most recognized green building certification programs, both nationally and internationally. It was developed by the US Green Building Council (USGBC) to provide a scale on which green practices in building could be measured, and to provide a support for owners wishing to achieve green standards.

LEED certification covers five primary categories covering the sustainability of a building. These categories include sustainable sites, water efficiency, energy and atmosphere, materials and resource credits, and indoor environmental quality. Additional 'extra credit' points can be earned through innovation and design and regional priorities. Credits include the environmental footprint of construction, modeled building envelope performance, educational initiatives, and locational characteristics. Points are awarded based on standards set by the USGBC. Minimum scores in each category must be met for a building to achieve certification. Additionally, the total score of a building determines certification levels, ranging from certified to Platinum.

Projects typically hire a LEED consultant or project manager to communicate expectations and documentation requirements to the builder, though many architecture and construction firms now offer this service in house. LEED project managers submit documentation for verification for each LEED credit they pursue after the design phase and again during the construction phase. Credits are reviewed individually by the USGBC. If the USGBC questions or denies that the criteria for a credit has been fulfilled, project managers can respond or appeal denied credits. While many credits are initially denied by the USGBC, project teams may withdraw those credits or produce documentation that verifies their accuracy. As a result, project teams, while 
aiming for the minimum score of a specific certification level, may often leave a cushion unless "the goal is to make the project the greenest project possible" [1].

From a builder's perspective, there are two clear benefits to green building: financial gains due to increased building performance and financial gains due to increased marketability.

Green buildings are thought have performance benefits such as lower operating costs with relatively low incremental construction costs [2]. By consuming significantly less energy, green buildings may be cost-effective [3] (however, recent research suggests that a "rebound effect" in newer or renovated buildings may actually increase total energy consumption, relative to buildings of an older vintage) [4]. And green building is thought to improve indoor air quality, health, and comfort [5][6]. Through these factors, productivity of green building occupants has been estimated to be 21 percent higher than conventional building occupants [2], leading to crude estimates of productivity gains between $\$ 40$ billion to $\$ 600$ billion annually in the United States [7].

Environmental rating schemes, such as the LEED certification program, serve to provide consumers with a basis for comparison among product alternatives [8]. Due to asymmetric information between building owners and prospective tenants or buyers, owners intending to lease or sell better-performing buildings struggle to recoup their investments when renters or buyers are uninformed or cannot verify the improvements [8-14]. With information asymmetry between owners and renters, LEED certification can signal renters about the quality or energy efficiency of the building [13]. Rents tend to rise with LEED points [15]. While LEED scoring allows owners (or builders) to transmit information to prospective tenants about energy efficiency of the building, the certification categories themselves transmit this information discontinuously. Consistent with research in information-based policies and environmental labeling programs, it may be that transmitting categorical LEED information conveys information more clearly to consumers than the raw LEED score (see $[16,17]$ for a discussion on 
information provision and eco-labeling). The prominence of these categories in shedding light on “green” facilities might also distort the signal and shape building owners’ incentives.

Current market pressures suggest a demand for and a supply of environmental goods, even if it means higher prices [18]. This can motivate firms to engage in "green” marketing, or green signaling, attempting to develop an environmentally conscious image, even if no environmental benefits result $[19,20]$. Research has suggested that green building certification of commercial buildings leads to a premium on rents and higher occupancy rates [21, 22], yet it is unknown how much of this benefit is due to improved performance of greener buildings versus the marketing benefits of green certification.

Given that certification itself is likely to be costly (e.g., obtaining LEED certification, at any level, is more costly than just making “green” investments without informing the US Green Building Council and getting a LEED score), presumably all certifications are sought for some green marketing benefit. A major question remains, however, how much of the certification is verifying the greener or better performance of the building and how much of the certification is signaling an image, status, or something else beyond performance? While all building owners receive some marketing benefit, the certification and signaling process provides uneven marketing benefits to building owners. Thus, even among those who are receiving some LEED marketing benefits through certification, we can examine the behavior of building owners at LEED scores that are on either side of the certification thresholds to understand the influence of green signaling on building owner behavior, in contrast to the certification of building performance. Further, the behavior may vary among different types of owners or building uses. While the numerical LEED score provides a verification of performance, the LEED certification provides a marketing signal. We assume that the performance benefits of LEED certified buildings are approximately equal on either side of the certification threshold; however, the green signaling or marketing benefits of certification may vary greatly, and provide motivation 
for the accumulation of additional LEED points to upgrade beyond the next certification threshold. The LEED certification program's scoring system offers an excellent opportunity to examine this question for one of the largest green certification programs for buildings in the world.

\section{Materials and Methods}

\section{A. Theoretical Model}

Consider a competitive firm that takes market price for its product $q$ as given at $p$. This profitmaximizing firm simultaneously chooses its output levels and also a level of investment in energy efficiency $e$. Our general model divides costs into two components: production costs $C(q, e)$ and energy efficiency investment costs $E(q, e)$. Let production costs $C$ be rising at an increasing rate in $q$, while $C$ is declining and decreasing rate in $e$. (In short, $C_{q}>0, C_{q q}>0, C_{e}<0$, $C_{e e}>0$.) This reflects diminishing returns to energy efficiency investments. Cost savings may involve more efficient or productive use of energy or water inputs, and it could include lower factor prices. Greater $e$ might make inputs like energy, water, or even labor cheaper and easier to employ (e.g., harvesting rainwater, rooftop solar panels, happier workers). Let energy investment costs rise at a nondeclining rate in $e$, while the scale of the firm $(q)$ leads to $E$ rising in $q$ at a nondeclining rate. (In short, $E_{e}>0, E_{e e} \geq 0, E_{q}>0, E_{q q} \geq 0$.) The intuition behind this model is that, given standard assumptions about rising production costs for a firm, energy efficiency investments translate into lower production costs but also incur the cost of that investment. The firm maximizes the profit (as described by equation 1 ) by choosing $q^{*}$ and $e^{*}$.

$$
\Pi=p q-C(q, e)-E(q, e)
$$

The firm's task is thus to jointly solve the two first-order conditions, equations (2) and (3):

$$
\Pi_{q}: p \leq C_{q}+E_{q}
$$




$$
\Pi_{e}: 0 \leq C_{e}+E_{e}
$$

Profits are maximized when price $p$ received for another unit of output is equated to the total (production and investment) costs incurred for that next unit of output, and when the cost savings from energy efficiency investment is equated to the incremental cost of that energy efficiency investment. The firm balances additional output's revenue against its costs while also balancing the up-front costs of additional energy efficiency investment against the cost-savings from improved performance on producing output. (The 0 in equation (3) results from the energy efficiency investment $e$ having no impact on sales price. We relax that assumption shortly.)

This basic model reflects a productive or cost-saving model for investments in $e$. However, the investment in $e$ may also give the firm a competitive advantage in the marketplace beyond any productivity impacts. Firms are often thought to benefit from a "green” signal to consumers from some form of eco-certification or conspicuous environmentally friendly investment. Firms that appear greener may be able to charge premiums for their products, boost demand and market share, or otherwise affect the price $p$ they charge. We model this similarly to monopolistic competition, where firms can charge a higher price for their output as their investment in energy efficiency increases (i.e., $d p / d e \equiv p_{e}>0, p_{e e}<0$ ). When $p_{e}>0$, then the left hand side of the inequality in equation (3) represents the additional per-unit-sold revenue effect (i.e., increase in price) of investments in $e$. We rewrite this as:

$$
\Pi_{e}: p_{e} q \leq C_{e}+E_{e}
$$

Now, profit-maximizing demands that they balance their cost-savings plus their added per-unit revenue against their investment costs for another unit of energy efficiency. As a result, as $p_{e}$ grows larger than zero, the optimal investment $e^{*}$ will also grow in order to maintain the equality 
in equation (3'). Intuitively, some investment in $e$ is worthwhile from purely a cost-savings standpoint. If that cost-savings investment also boosts demand for the product, then profitmaximizing firms would increase their use of $e$ until the returns to additional $e$ (higher revenues, lower costs) equal its investment costs. This model extends readily to include building developers or landlords, whose output $(q)$ are facilities sold or rented to tenants.

When $p_{e}$ falls to zero - there is no market advantage from additional increments of investment in $e$ - we expect $e^{*}$ to fall. This consequence from information asymmetries between owners and renters is well established $[9,13]$. This can be particularly important if the green signaling provided by $e$ discontinuously occurs when some threshold of $e$ has been passed - (i.e. when the firm gets enough points for certification). The discontinuous or "lumpy" nature of the impact of additional $e$ on $p$, which seems to best describe green signaling mechanisms, complicates the first-order conditions above, which conveniently assume continuously differentiable functions. In the more discrete set-up, we expect to see that $e^{*}$ rises when $p_{e}>0$ but, once the threshold is passed and there are no additional price premiums associated with incremental investments in $e$, the firm would stop buying more $e$ (except insofar as it confers profitable cost savings per equation (3)). In an extreme example where $C_{e}=0$ and $p_{e}>0$, we would expect the firm to invest up until the threshold where the revenue gains are at least as big as the cost to achieve that

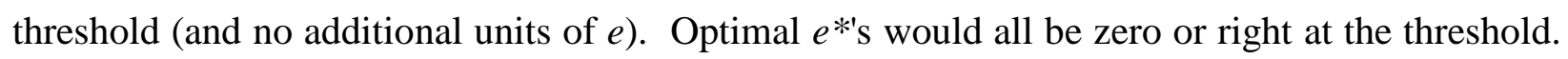
At the other extreme where $C_{e}<0$ and $p_{e}=0$, then we would expect firms' investment $e^{*}$ to vary more continuously as their production and investment costs vary. Likely, the reality is somewhere in between these two extremes, and we should see some (but not perfect) clustering in $e^{*}$ values around the certification threshold(s). Regardless, when prices jump up as a threshold is crossed, this provides additional incentive to upgrade categories relative to what we would observe with no discontinuities around categories. 
Many green building projects are undertaken by government authorities or nonprofits, and the previous profit-maximizing model may not apply well. Instead, consider nonprofit or government agency seeking to maximize its output while otherwise facing the same decisions as the for-profit firm. The optimization problem is a slightly more complex Lagrangian in equation (4):

$$
\mathfrak{I}=q+\lambda(p q-C(q, e)-E(q, e))
$$

The first-order conditions are:

$$
\begin{aligned}
& \mathfrak{I}_{q}: 1 \leq-\lambda\left(p-C_{q}-E_{q}\right) \Rightarrow p+1 / \lambda \leq C_{q}+E_{q} \\
& \mathfrak{I}_{e}: 0 \leq-\lambda\left(p_{e} q-C_{e}-E_{e}\right) \Rightarrow p_{e} q \leq C_{e}+E_{e}
\end{aligned}
$$

so (5) is like (2) except that optimal costs for additional units of output will exceed costs, which means that $q$ will have to expand (relative to equation (2)'s solution) to keep the equality. Equation (6) still has the output-maximizing agency green signaling in order to boost demand for their output and thus enable them to expand their output (via improved profits and a relaxed constraint). The model predictions for output-maximizing agencies closely resemble those for profit-maximizing firms, and the intuitions remain as long agencies still face budget constraints, though recent research suggests that for energy consumption, government tenants have a less elastic demand for building electricity consumption [4]. In other words, agencies still care to lower costs or raise prices insofar as it affords them the opportunity to increase output (rather than increase profits, as we expect from for-profit firms). Nonprofit or government agencies still balance the energy efficiency investment costs against their productivity gains and their marketing gains. Government agencies and non-profits, for example, may seek to improve awareness of service availability, improve the desirability of their services, or increase their appeal to stakeholders. Whether there is more or less green signaling by for-profit firms, 
compared to output-maximizing agencies, depends on many factors, such as their respective technologies, costs, demands faced, and marketing advantages from green signaling. We test this question empirically as part of this analysis.

How much of LEED certification is due to $e$ as a productive input and how much is due to $e$ as a green signal? To observe this, we observe the amount of clustering around the thresholds and compare the number of firms at those thresholds to what we might otherwise expect from a smooth distribution of $e$ values. Two aspects of the LEED program design - discontinuous marketing benefits from additional points at the thresholds and no discontinuity in productivity benefits from additional points at the thresholds - allow us to identify the marketing advantages around the thresholds.

B. Data

Data on LEED projects are gathered from the USGBC website. The data available include the total LEED project score as well as some project details, such as the location, size, and owner details.

To generate a consistent sample, the data analyzed are limited to New Construction projects that fell under the scoring versions 2.0 through 2.2. The data are then split into categories based on ownership type. The categories analyzed are:

All New Construction (NC)

Government Buildings (G)

Non-Profit (NP)

For Profit (P)

Other (O) 
The scoring system for New Construction, Versions 2.0-2.2, allows 69 total possible points, with scores of 26-32 earning certification, scores of 33-38 earning silver certification, scores of 39-51 earning gold certification, and scores of 52 or higher earning platinum certification.

Data are plotted as a histogram with USGBC point totals on the x-axis, and the number of buildings achieving that score on the y-axis. The large spikes in density just to the right of thresholds garnering higher certification levels provide the most immediate evidence that signaling via levels or colors plays a prominent role in LEED certification.

<insert Table 1 about here (descriptive stats)>

Of 5,238 total projects, 36.4 percent of projects were completed by government agencies, 34.2 percent by for profit entities, and 19.8 percent by non-profit organizations. A small number (7 percent) did not have available ownership information. On average, buildings scored approximately 37 LEED points, with Non-profit organizations scoring slightly higher than Government agencies or for-profit entities. For the entire sample, 20.8 percent of buildings were certified, 34.3 percent were silver certified, 39.7 percent were gold certified, and 5.3 percent received platinum certification. Non-profit organizations were twice as likely to attain Platinum certification compared with Government or For-profit buildings.

\section{Methods}

We estimate the amount of LEED certifications attributable to $e$ as a productive input (including both marketing and performance benefits) by dropping the certifications that occur just above or below the threshold certification levels from the dataset. The logic here is that the thresholds introduce a discontinuity in the returns to higher points entirely due to enhanced status or signaling associated with a higher certification level. Thus we seek to estimate the density of observations at points around the thresholds as if there were no threshold effects (i.e., the density 
was smooth in the neighborhood of the threshold). To calculate the predicted expectation of LEED points earned, conditional on there being no discontinuity or signaling mechanism, we estimate a kernel density function using MATLAB. The nonparametric kernel density estimates a locally smooth density estimation based solely on the observed distribution of certification scores [23]. This kernel density function removes the "lumpiness" caused by the threshold signal effects and represents the amount of LEED certification we might expect if $e$ was merely a productive input with no special signal for crossing an arbitrary threshold. We multiply the kernel density function (which has a total area of 1 ) by the total number of projects to estimate the expected value of the total number of projects due to investments in e.

In the spirit of regression discontinuity design [24] we identify the portion of marketing effects provided by the green signal on building behavior by calculating the difference between the observed number of buildings at each certification level and the number of buildings predicted by the kernel density function that disregards threshold effects. We assume that without signaling from crossing a certification threshold, the productive benefits of investments in additional $e$ vary continuously on either side of the certification threshold. Put another way, the additional returns from achieving a score of 38 rather than a 37 (LEED silver) ought to be roughly similar to the additional returns to achieving a score of 39 (LEED gold) rather than a 38 - except for marketing advantages conferred by the higher certification status. The empirical density, which might contain sharp discontinuities around the threshold, can be compared to identify any unexpectedly high or low frequencies of LEED scores. Some, but not all, observations at threshold scores are "stacked” there because of green signaling benefits. This approach likely overstates the frequency scores just above LEED category thresholds, thus yielding conservative estimates of the signaling effect.

The analysis of discontinuities at the thresholds extends beyond the central question of densities and observations stacking up just above thresholds. We use a nonparametric regression 
discontinuity design $[22,23]$ to explore other discontinuities at the thresholds. Evidence that building projects’ observable characteristics differ significantly on either side of the threshold offers a test of sorting behavior around the marketing advantages of LEED classifications. The test compares the expected values of project characteristics just above and just below each threshold based on locally smoothed regressions using data from only above and only below, respectively, with standard errors computed as in [22]. There should be no difference if project attributes do not jump at the threshold. The results indicate more than just increased density above the thresholds. They inform which types of projects and organizations are more likely to "upgrade” to point totals above thresholds.

\section{Results}

$<<$ insert Tables 2 \& 3 here $>>$

$<<$ insert Figure 1 about here $>>$

When the buildings earning the two lowest and highest scores in each category are excluded and remaining scores are used to calculate a kernel density function as a comparison to actual scores, we find evidence of green signaling around the thresholds for all certification levels. Results are not sensitive to dropping one value on either side of a threshold or dropping two values on either side to generate the kernel density function (see figure 1 versus figure SI1). For simplicity, we present and interpret the results generated by the kernel density function that drops the 2 highest and lowest LEED certification scores on either side of the threshold (presented in Tables 1 and 2, and visualized in Figure 1). Results from the kernel density function that drops highest and lowest scores on either side of the threshold have similar results and are included in Figure SI1. Dropping more scores leads to a flatter counterfactual (i.e., efficiency gains only) distribution in Figure 1, and likely a better estimate of signaling effects, 
although the approach of dropping fewer scores (Figure SI1) offers a more conservative estimate of signaling effects.

The green signal produces large 'stacks' of observations at the thresholds for all certification levels, with sharper drop-offs in frequencies evident for gold and platinum certification levels than lower categories. Signaling across the distribution produces 15.2 percent (798 total buildings) excess certifications earning the point total just above a threshold, and an additional 3.7 (215 total buildings) percent excess certifications earning the second least points in each certification level. Thus, almost 19 percent of building projects' LEED scores are higher than they otherwise would be due to the signaling motivation. One in five buildings are "greener" than they would otherwise be due to the signaling effect of LEED.

The signaling mechanism is consistent across subsamples, with all types of building clustering just above the thresholds regardless of owner type (see figures 3, 4, and 5). Following the methodology described in [23], we demonstrate differences in the typical building characteristics on either side of the threshold. Table 4 displays the results. By testing for differences in the expected value of the frequency of buildings on either side of the threshold, the greater share of buildings built at each of the three LEED thresholds (Silver, Gold, and Platinum) confirm this (at $\mathrm{p}$ values less than 0.01). To further demonstrate how clustering of values is confined to just above thresholds, we conduct a falsification test using a fourth "threshold," an arbitrary point total of 43. At this non-threshold point, there is no statistically significant signaling consistent with greater building shares $(\mathrm{p}=0.79)$.

\section{$<<$ insert Table 4 about here $>>$}

Overall building patterns and signaling behavior appear to vary across ownership. Non-profit organizations tend to build a higher percentage of buildings earning Platinum certification and pursue green signals more than for-profit or government agencies. Non-profit institutions have a 13.2 percent signaling effect at the lowest point total and a 8.7 percent signaling effect at the 
second lowest point total. Government agencies have a total signaling effect of 14.5 percent across all categories at the lowest point total and an additional 4.9 percent at the second lowest total. For profit entities have a 13.1 percent signaling effect at the lowest point total and an additional 5.2 percent at the second lowest point total for each certification level. Figures demonstrating clustering by different types of organizations are included in the Supporting Information.

The RD analysis in Table 4 shows that projects with certain building characteristics exhibiting signaling behavior at the thresholds. Governments tend not to signal at the Gold or Platinum levels. For profit firms tend to signal at all levels. College campuses are tend to signal at Gold and Platinum levels. Commercial buildings tend to signal at Silver and Platinum levels (but not Gold). Health care buildings are less likely to signal at Silver and Platinum levels. Hotels and resorts tend to signal at the Platinum level exclusively. Parks and stadiums tend to signal at the Gold level, and restaurants tend to signal at all levels. Results for these findings are consistent across bandwidths.

\section{Discussion}

The results consistently show that large numbers of buildings cluster at or above the cut off points for each certification level, and few buildings cluster just below the cut off points for each certification level. Nonparametric regression discontinuity analysis confirms this finding for all three thresholds at $\alpha=0.01$. Because the kernel density function represents the locally smoothed density - an approximation of cost-effective performance benefits of LEED certification - these point clusters at the certification thresholds support the claim that many building owners seek green building certification levels in order to improve marketability, rather than merely to improve performance. When the expected point total of a building is just below the threshold, building owners often shift behavior to achieve point totals exceeding the next certification level. 
The data also show some buildings that earn points in the higher end of the point range within each certification level. This distribution supports the idea that some building owners seek LEED certification but do not pay as close attention to the specific thresholds, trying to build the greenest building possible. However, because certification occurs after building construction, some firms may fall short of their target certification level, and may not be able to reach the next highest threshold. This behavior supports the idea that performance benefits drive at least a portion of certification behavior. In contrast, evidence from prior research suggests that project owners choose target certification levels and subsequently select LEED criteria to reach target certification levels [25]. Our results suggest a combination of these behaviors.

Across ownership types, non-profit institutions build a larger percentage of LEED buildings that are Platinum certified, have a higher average point total, and also employ the strongest green signal at the highest levels of certification. That non-profit organizations are more likely to build a Platinum certified building than a for-profit entity is not surprising - the social mission of a non-profit organization may place a higher value on social benefits than a for-profit entity. Forprofit firms tend to signal at all three certification levels, highlighting concerns regarding corporate greenwashing [26]. The stronger interest in sending green signals by the non-profits than the for-profits (21.9 percent vs. 18.3 percent, when counting the two lowest point totals in each category), is surprising, though the reliance of non-profit institutions on donors and external stakeholders may also lead to a greater signaling pressure. Government agencies, interestingly, tend not to signal at Gold and Platinum levels. This finding suggests that while public building standards may require or promote LEED certification, Gold and Platinum certification may not be justifiable as public officials use taxpayer funding.

The RD results also demonstrate different sensitivities to signaling motivations for different building types. Campuses and higher education signaling at the Gold and Platinum levels is unsurprising given universities' motivations to achieve leadership in green building and to 
market signals to internal (e.g., students pressuring for sustainability) and external (e.g., those giving campus sustainability awards) stakeholders. Commercial buildings tend to signal at the Silver or Platinum levels, suggesting that there are marketing gains to LEED certification [15, 22], and premium gains for Platinum certification. Restaurants signal at all three levels, perhaps demonstrating the marketing gains and user experience associated in a LEED building. Stadiums tend to certify at the Gold levels, perhaps reflecting environmental marketing efforts by professional sports [27] and larger financial gains available in high profile building uses. Similarly, hotels and resorts tend to signal at the Platinum level, suggesting a premium or exclusive marketing niche. Interestingly, health care buildings tend not to signal at Silver and Platinum levels (and at Gold exhibit a negative parameter coefficient). This suggests that the healthcare sector lags behind other sectors in environmental marketing, pays more attention to performance benefits of green building, and represents healthcare's peculiar circumstance where administration faces constraints from insurance companies and government regulators. (Strict rules on chargeable rates may prevent cost recovery for upgrades to $e$, such that $p_{e} q$ falls to zero, so health care buildings are less likely to pursue green signals than other buildings.)

Table 4 makes clear that the impetus to "upgrade" and achieve more marketable levels of certification is not evenly distributed across all projects. Some types of projects and owners appear more sensitive to threshold effects than others. Thus, care should be taken in attributing differences in outcomes like energy efficiency, profitability, and even prices to LEED certification, because LEED category attainment is hardly independent of other key project characteristics.

Marketing plays a very large role in motivating building owners to obtain LEED certification, but marketing benefits appear to raise LEED certification to higher point levels than we would otherwise expect, emphasizing that buildings are built "greener" due to LEED certification thresholds than they would otherwise have been built. Our evidence suggests that a total of 15 to 
20 percent of LEED-certified buildings are achieving higher point totals than would be expected without the signaling that green certification provides. Across the entire distribution, a minimum of 1,570 to 4,190 additional LEED points are likely attributable to this signaling mechanism. In light of an efficiency paradox, where investment in energy-efficient buildings are thought to be under-invested in society, this points to an important role of green marketing in addressing efficiency investment deficits.

\section{References}

1. Interview with LEED Technical Resources Manager, In 2013.

2. Srinivas, S., Green Buildings - Benefits and Impacts. Proceedings of World Academy of Science: Engineering \& Technology 2009, 51, 790-795.

3. $\quad$ Ries, R.; Bilec, M. M.; Gokhan, N. M.; Needy, K. L., The Economic Benefits of Green Buildings: A Comprehensive Case Study. The Engineering Economist 2006, (51), 259-296.

4. $\quad$ Kahn, M. E.; Kok, N.; Quigley, J. M. Commercial Building Electricity Consumption Dynamics: The Role of Structure Quality, Human Capital, and Contract Incentives; National Bureau of Economic Research: 2013.

5. Cidell, J.; Beata, A., Spatial Variation Among Green Building Certification Categories: Does place matter? Landscape and Urban Planning 2009, 91, (3), 142-151.

6. $\quad$ Cole, R. J., Emerging Trends in Building Environmental Assessment Methods. Building and Research Information 1998, 26, (1), 3-16.

7. Fisk, W. J., Health and Productivity Gains from Better Indoor Environments and their Relationship with Building Energy Efficiency. Annual Review of Energy and the Environment 2000, 25, 537-566.

8. Crawley, D.; Aho, I., Building environmental assessment methods: applications and development trends. Building Research \& Information 1999, 27, (4/5), 300-308.

9. Levinson, A.; Niemann, S., Energy use by apartment tenants when landlords pay for utilities. Resource and Energy Economics 2004, 26, (1), 51-75.

10. Howarth, R. B.; Sanstad, A. H., Discount Rates and Energy Efficiency. Contemporary Economic Policy 1995, 13, (3), 101-109.

11. Howarth, R. B.; Andersson, B., Market Barriers to Energy Efficiency. Energy Economics 1993, 15, (4), 262-272.

12. Gillingham, K.; Newell, R. G.; Palmer, K., Energy Efficiency Economics and Policy. Annual Review of Resource Economics 2009, 1, (1), 597-620.

13. Davis, L. W., Evaluating the Slow Adoption of Energy Efficient Investments: are renters less likely to have energy efficient appliances? In The Design and Implementation of US Climate Policy, University of Chicago Press: 2011; pp 301-316.

14. Allcott, H.; Greenstone, M. Is there an energy efficiency gap?; National Bureau of Economic Research: 2012.

15. Eichholtz, P.; Kok, N.; Quigley, J. M., Doing well by doing good? Green office buildings. The American Economic Review 2010, 100, (5), 2492-2509. 
16. Bae, H.; Wilcoxen, P. J.; Popp, D., Information Disclosure Policy: Do State Data Processing Efforts Help More than the Information Disclosure Itself. Journal of Policy Analysis and Management 2010, 29, (1), 163-182.

17. Mason, C. F.; Calvo, E.; Rubio, S. J.; Zhang, Z. X., The Economics of Eco-Labeling: Theory and Empirical Implications. Economics 2013, 6, (4).

18. Majumdar, S.; Zhang, Y., Market for Green Signaling. The Buisiness Review, Cambridge 2009, 13, 87-92.

19. Saha, M.; Darnton, G., Green Companies or Green Con-panies: Are Companies Really Green, or Are They Pretending to Be? Business and Society Review 2005, 110, (2), 117-157.

20. Rivera, J.; De Leon, P.; Koerber, C., Is Greener Whiter Yet? The Sustainable Slopes Program After Five Years. Policy Studies Journal 2006, 34, (2), 195-221.

21. Fuerst, F.; McAllister, P., Green Noise or Green Value? Measuring the Effects of Environmental Certification on Office Values. Real Estate Economics 2011, 39, (1), 45-69.

22. Eichholtz, P.; Kok, N.; Quigley, J. M., The economics of green building. Review of Economics and Statistics 2013, 95, (1), 50-63.

23. Silverman, B. W., Using Kernel Density Estimates to investigate Multimodality. Journal of the Royal Statistical Society 1981, 43, (1), 97-99.

24. Hahn, J.; Todd, P.; Van der Klaauw, W., Identification and Estimation of Treatment Effects with a Regression-Discontinuity Design. Econometrica 2001, 69, (1), 201-209.

25. Corbett, C. J.; Muthulingam, S., Adoption of Voluntary Environmental Standards: The Role of Signaling and Intrinsic Benefits in the Diffusion of the LEED Green Building Standards. 2007.

26. $\quad$ Pearse, G., Greenwash: Big Brands and Carbon Scams. Black Inc.: 2012.

27. National Basketball Media Ventures LLC NBA Green Inititaive. http://www.nba.com/green/mission.html (September 6, 2013),

28. Health Care Without Harm Issues in Green Building: Energy Efficiency. http://www.noharm.org/us_canada/issues/building/efficiency.php (September 6, 2013), 
Table 1. Descriptive Statistics

\begin{tabular}{|l|l|l|l|l|l|}
\hline & All & Government & For Profit & Non Profit & Other \\
\hline Total Projects & 5238 & 1910 & 1790 & 1038 & 385 \\
\hline Mean & 37.04 & 37.07 & 36.44 & 37.89 & 36.88 \\
\hline $\begin{array}{l}\text { Standard } \\
\text { Deviation }\end{array}$ & 6.71 & 6.51 & 6.55 & 7.57 & 6.91 \\
\hline $\begin{array}{l}\text { Percent } \\
\text { Certified }\end{array}$ & 20.79 & 18.64 & 23.41 & 20.62 & 21.04 \\
\hline $\begin{array}{l}\text { Percent Silver } \\
\text { Percent Gold }\end{array}$ & 34.27 & 35.86 & 35.87 & 29.67 & 32.21 \\
\hline $\begin{array}{l}\text { Percent } \\
\text { Platinum }\end{array}$ & 5.25 & 4.19 & 36.37 & 40.94 & 41.82 \\
\hline
\end{tabular}


Table 2: All New Construction, Buildings Earning Lowest and Second Lowest / Highest Scores in Each Category Excluded

\begin{tabular}{|c|c|c|c|c|}
\hline & Points Earned & Actual & Predicted & Difference \\
\hline & 25 & 1 & 26 & -25 \\
\hline & & & & \\
\hline \multirow{7}{*}{ | } & 26 & 243 & 70 & 173 \\
\hline & 27 & 178 & 140 & 38 \\
\hline & 28 & 195 & 207 & -12 \\
\hline & 29 & 164 & 231 & -67 \\
\hline & 30 & 147 & 198 & -50 \\
\hline & 31 & 96 & 138 & -40 \\
\hline & 32 & 66 & 108 & -42 \\
\hline & & & & \\
\hline \multirow{6}{*}{$\frac{\vec{D}}{i=}$} & 33 & 494 & 148 & 346 \\
\hline & 34 & 430 & 243 & 187 \\
\hline & 35 & 384 & 323 & 61 \\
\hline & 36 & 289 & 317 & -26 \\
\hline & 37 & 150 & 231 & -81 \\
\hline & 38 & 48 & 151 & -102 \\
\hline & & & & \\
\hline \multirow{13}{*}{ 픙 } & 39 & 523 & 147 & 376 \\
\hline & 40 & 437 & 223 & 214 \\
\hline & 41 & 287 & 325 & -38 \\
\hline & 42 & 258 & 383 & -125 \\
\hline & 43 & 192 & 369 & -177 \\
\hline & 44 & 131 & 306 & -175 \\
\hline & 45 & 94 & 229 & -135 \\
\hline & 46 & 65 & 162 & -97 \\
\hline & 47 & 41 & 109 & -68 \\
\hline & 48 & 27 & 69 & -42 \\
\hline & 49 & 16 & 41 & -25 \\
\hline & 50 & 6 & 22 & -16 \\
\hline & 51 & 1 & 14 & -13 \\
\hline & & & & \\
\hline \multirow{13}{*}{$\begin{array}{c}\text { 园 } \\
\text { 吢 } \\
\mathbf{a}\end{array}$} & 52 & 65 & 18 & 47 \\
\hline & 53 & 65 & 31 & 34 \\
\hline & 54 & 44 & 46 & -2 \\
\hline & 55 & 34 & 52 & -18 \\
\hline & 56 & 22 & 50 & -28 \\
\hline & 57 & 23 & 40 & -17 \\
\hline & 58 & 8 & 28 & -20 \\
\hline & 59 & 6 & 18 & -12 \\
\hline & 60 & 4 & 11 & -7 \\
\hline & 61 & 2 & 7 & -5 \\
\hline & 62 & 1 & 4 & -3 \\
\hline & 63 & 1 & 2 & -1 \\
\hline & 64 & 0 & 1 & -1 \\
\hline
\end{tabular}


Table 3: Difference between Actual and Kernel Density Projected as a Percentage of Total Projects, Ownership Type Comparison, 2 lowest and highest point possibilities dropped

\begin{tabular}{|c|c|c|c|c|c|}
\hline & Points Earned & All NC & Government & For Profit & Non Profit \\
\hline & 25 & -0.5 & -0.7 & -1.5 & -1.1 \\
\hline \multirow{7}{*}{ 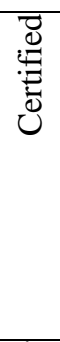 } & 26 & 3.3 & 3.2 & 2.9 & 3.4 \\
\hline & 27 & 0.7 & 0.6 & 0.9 & 1.6 \\
\hline & 28 & -0.2 & 0.3 & 1.3 & 0.7 \\
\hline & 29 & -1.3 & -0.4 & -1.1 & 0.5 \\
\hline & 30 & -1.0 & -1.0 & 0.1 & -0.7 \\
\hline & 31 & -0.8 & -0.8 & -2.7 & -0.9 \\
\hline & 32 & -0.8 & -1.7 & -3.2 & -1.0 \\
\hline \multirow{6}{*}{$\frac{\bar{d}}{\overline{0}}$} & 33 & 6.6 & 6.0 & 7.7 & 6.3 \\
\hline & 34 & 3.6 & 4.2 & 2.9 & 5.9 \\
\hline & 35 & 1.2 & 2.7 & 4.0 & 1.3 \\
\hline & 36 & -0.5 & -0.2 & 1.3 & 1.0 \\
\hline & 37 & -1.5 & -1.4 & -2.0 & -1.5 \\
\hline & 38 & -1.9 & -2.8 & -4.4 & -2.8 \\
\hline \multirow{13}{*}{$\begin{array}{l}\text { 궁 } \\
0\end{array}$} & 39 & 7.2 & 6.3 & 6.2 & 5.2 \\
\hline & 40 & 4.1 & 3.2 & 5.5 & 3.2 \\
\hline & 41 & -0.7 & -0.6 & 0.6 & 0.1 \\
\hline & 42 & -2.4 & -1.2 & -1.1 & -1.3 \\
\hline & 43 & -3.4 & -3.0 & -2.8 & -1.3 \\
\hline & 44 & -3.3 & -3.7 & -2.7 & -2.7 \\
\hline & 45 & -2.6 & -2.9 & -2.7 & -2.7 \\
\hline & 46 & -1.8 & -1.9 & -2.4 & -2.4 \\
\hline & 47 & -1.3 & -1.7 & -1.5 & -2.0 \\
\hline & 48 & -0.8 & -0.9 & -1.3 & -1.8 \\
\hline & 49 & -0.5 & -0.6 & -0.8 & -1.1 \\
\hline & 50 & -0.3 & -0.3 & -0.7 & -1.2 \\
\hline & 51 & -0.2 & -0.4 & -0.6 & -1.0 \\
\hline \multirow{13}{*}{ 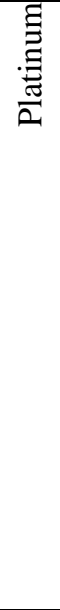 } & 52 & 0.9 & 0.8 & 0.9 & 0.6 \\
\hline & 53 & 0.6 & 0.5 & 0.4 & 1.0 \\
\hline & 54 & 0.0 & 0.1 & 0.1 & 0.1 \\
\hline & 55 & -0.3 & -0.2 & -0.1 & -0.2 \\
\hline & 56 & -0.5 & -0.3 & -0.3 & -0.7 \\
\hline & 57 & -0.3 & -0.3 & -0.4 & 0.0 \\
\hline & 58 & -0.4 & -0.3 & -0.2 & -0.9 \\
\hline & 59 & -0.2 & -0.2 & -0.3 & -0.7 \\
\hline & 60 & -0.1 & -0.1 & -0.2 & -0.5 \\
\hline & 61 & -0.1 & -0.1 & -0.2 & -0.2 \\
\hline & 62 & -0.1 & -0.1 & -0.1 & -0.3 \\
\hline & 63 & 0.0 & 0.0 & -0.1 & -0.1 \\
\hline & 64 & 0.0 & 0.0 & -0.1 & -0.1 \\
\hline
\end{tabular}


Table 4. Tests for discontinuities at each of the LEED thresholds (Silver, Gold, and Platinum), as well as an arbitrarily determined point total (43). Bandwidth is four. "Mean" represents the expected share of all buildings (for "Building Share”) or the expected proportion of buildings with that attribute (for all others) at the threshold; "alpha” represents the difference between the expected and observed proportions at the threshold. Bold indicates statistical significance at $\alpha=0.10$, for each of the variables.

\begin{tabular}{|c|c|c|c|c|c|c|c|c|c|c|c|c|}
\hline \multirow[b]{2}{*}{ Variable } & \multicolumn{3}{|c|}{ Silver (33) } & \multicolumn{3}{|c|}{ Gold (39) } & \multicolumn{3}{|c|}{ Platinum (52) } & \multicolumn{3}{|c|}{ Random (43) } \\
\hline & mean & alpha & $\mathrm{p}$ & mean & alpha & $\mathrm{p}$ & mean & alpha & $\mathrm{p}$ & mean & alpha & $\mathrm{p}$ \\
\hline $\begin{array}{l}\text { Building } \\
\text { Share }\end{array}$ & 0.004 & 0.09 & 0.00 & -0.014 & 0.11 & 0.00 & -0.003 & 0.02 & 0.00 & 0.030 & 0.01 & 0.79 \\
\hline Govt & 0.386 & 0.02 & 0.59 & 0.509 & -0.10 & 0.03 & 1.625 & -1.23 & 0.00 & 0.513 & -0.10 & 0.08 \\
\hline For Profit & 0.252 & 0.12 & 0.01 & 0.301 & 0.08 & 0.09 & 0.000 & 0.32 & 0.01 & 0.283 & 0.03 & 0.64 \\
\hline Non-Profit & 0.362 & -0.15 & 0.00 & 0.191 & 0.03 & 0.50 & -0.625 & 0.92 & 0.00 & 0.204 & 0.08 & 0.12 \\
\hline Campus & 0.113 & -0.01 & 0.57 & 0.013 & 0.11 & 0.00 & 0.000 & 0.18 & 0.09 & 0.199 & -0.01 & 0.84 \\
\hline $\begin{array}{l}\text { Commerci } \\
\text { al }\end{array}$ & 0.220 & 0.08 & 0.05 & 0.258 & 0.05 & 0.24 & 0.000 & 0.36 & 0.00 & 0.368 & 0.00 & 0.95 \\
\hline $\begin{array}{l}\text { Health } \\
\text { Care }\end{array}$ & 0.107 & -0.05 & 0.05 & 0.072 & -0.01 & 0.69 & 0.375 & -0.35 & 0.00 & 0.030 & 0.00 & 0.92 \\
\hline Higher Ed & 0.127 & 0.01 & 0.87 & 0.038 & 0.13 & 0.00 & 0.125 & 0.11 & 0.35 & 0.183 & 0.06 & 0.20 \\
\hline $\begin{array}{l}\text { Hotel \& } \\
\text { Resort }\end{array}$ & 0.035 & -0.01 & 0.68 & 0.021 & 0.00 & 0.70 & -0.125 & 0.14 & 0.00 & 0.012 & 0.00 & 0.82 \\
\hline Park & 0.015 & 0.01 & 0.55 & 0.004 & 0.02 & 0.06 & 0.000 & 0.04 & 0.39 & 0.022 & 0.00 & 0.93 \\
\hline Restaurant & -0.015 & 0.06 & 0.00 & -0.004 & 0.04 & 0.00 & -0.250 & 0.27 & 0.00 & 0.040 & -0.01 & 0.55 \\
\hline Stadium & 0.000 & 0.00 & 0.40 & -0.013 & 0.02 & 0.01 & N/A & N/A & N/A & 0.016 & -0.01 & 0.14 \\
\hline
\end{tabular}


Figure 1: Point Distribution for All New Construction with Kernel Density Curve, two lowest / highest score possibilities dropped

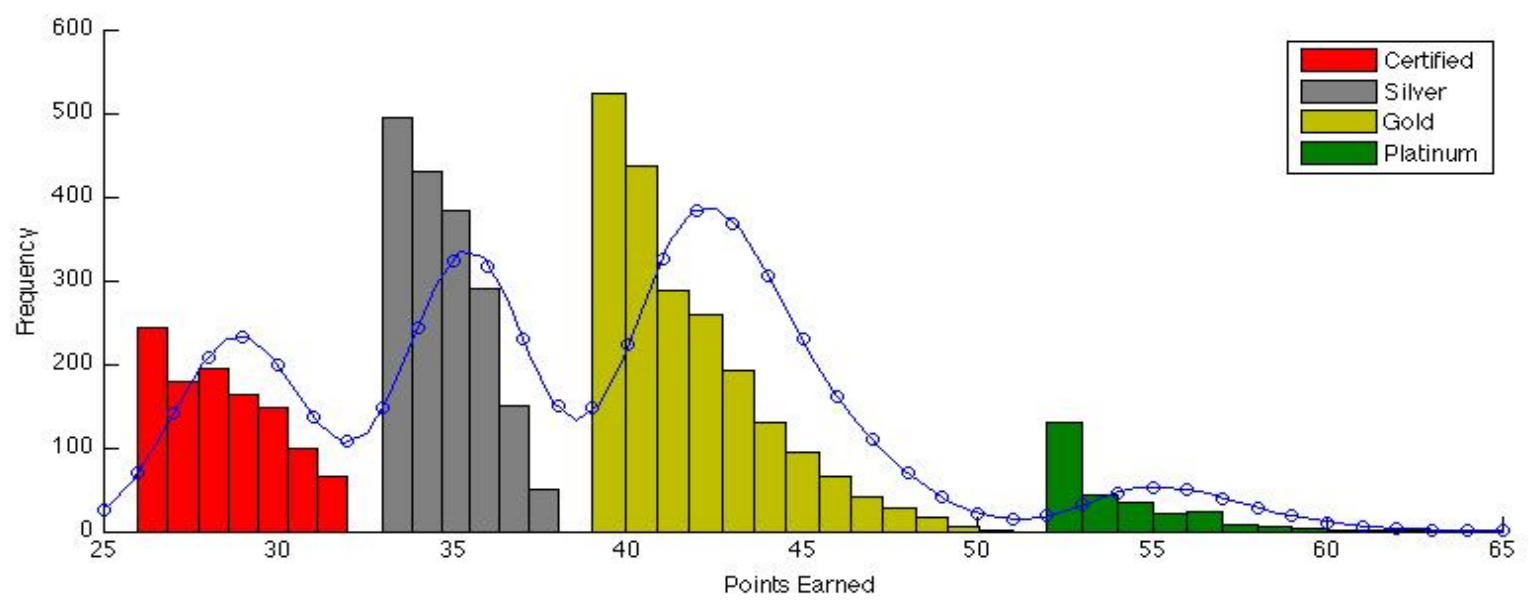




\section{Supporting Information}

Table SI1: New Construction, Buildings Earning Lowest and Highest Score In Each Category

Excluded

\begin{tabular}{|c|c|c|c|c|}
\hline & Points Earned & Actual & Predicted & Difference \\
\hline & 25 & 1 & 26 & -25 \\
\hline \multirow{8}{*}{ 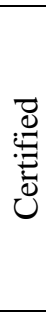 } & & & & \\
\hline & 26 & 243 & 85 & 158 \\
\hline & 27 & 178 & 165 & 13 \\
\hline & 28 & 195 & 217 & -22 \\
\hline & 29 & 164 & 216 & -52 \\
\hline & 30 & 147 & 179 & -31 \\
\hline & 31 & 96 & 128 & -30 \\
\hline & 32 & 66 & 112 & -46 \\
\hline \multirow{6}{*}{$\frac{\bar{d}}{\grave{i}}$} & 33 & 494 & 209 & 285 \\
\hline & 34 & 430 & 356 & $\begin{array}{r}205 \\
74\end{array}$ \\
\hline & 35 & 384 & 420 & -36 \\
\hline & 36 & 289 & 354 & -63 \\
\hline & 37 & 150 & 227 & -77 \\
\hline & 38 & 48 & 155 & -106 \\
\hline & & & & \\
\hline \multirow{13}{*}{$\begin{array}{l}\text { 등 } \\
ن \\
ن\end{array}$} & 39 & 523 & 205 & 318 \\
\hline & 40 & 437 & 326 & 111 \\
\hline & 41 & 287 & 380 & -93 \\
\hline & 42 & 258 & 339 & -81 \\
\hline & 43 & 192 & 268 & -76 \\
\hline & 44 & 131 & 198 & -67 \\
\hline & 45 & 94 & 140 & -46 \\
\hline & 46 & 65 & 97 & -32 \\
\hline & 47 & 41 & 65 & -24 \\
\hline & 48 & 27 & 41 & -14 \\
\hline & 49 & 16 & 25 & -9 \\
\hline & 50 & 6 & 14 & -8 \\
\hline & 51 & 1 & 14 & -13 \\
\hline \multirow{13}{*}{ 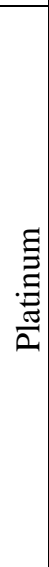 } & 52 & 65 & 28 & 37 \\
\hline & 53 & 65 & 48 & 17 \\
\hline & 54 & 44 & 54 & -10 \\
\hline & 55 & 34 & 47 & -13 \\
\hline & 56 & 22 & 36 & -14 \\
\hline & 57 & 23 & 26 & -3 \\
\hline & 58 & 8 & 17 & -9 \\
\hline & 59 & 6 & 10 & -4 \\
\hline & 60 & 4 & 6 & -2 \\
\hline & 61 & 2 & 4 & -2 \\
\hline & 62 & 1 & 2 & -1 \\
\hline & 63 & 1 & 1 & 0 \\
\hline & 64 & 0 & 0 & 0 \\
\hline
\end{tabular}


Table SI2 Difference between Actual and Kernel Density Projected as a Percentage of Total Projects, Ownership Type Comparison, lowest and highest point possibility dropped

\begin{tabular}{|c|c|c|c|c|c|}
\hline & $\begin{array}{l}\text { Points } \\
\text { Earned }\end{array}$ & $\begin{array}{l}\text { All New } \\
\text { Construction }\end{array}$ & Government & For Profit & Non Profit \\
\hline & 25 & -0.5 & -0.7 & -1.1 & -1.1 \\
\hline \multirow{7}{*}{ نِّ: } & 26 & 3.1 & 3.1 & 2.2 & 3.2 \\
\hline & 27 & 0.4 & 0.3 & 0.4 & 1.3 \\
\hline & 28 & -0.2 & 0.0 & 0.8 & 0.2 \\
\hline & 29 & -0.9 & -0.5 & -0.9 & 0.0 \\
\hline & 30 & -0.6 & -0.8 & 0.3 & -1.2 \\
\hline & 31 & -0.8 & -0.6 & -1.7 & -1.4 \\
\hline & 32 & -1.4 & -1.9 & -2.3 & -1.9 \\
\hline \multirow{6}{*}{$\stackrel{\vec{D}}{\vec{\omega}}$} & 33 & 5.3 & 4.9 & 5.9 & 4.8 \\
\hline & 34 & 1.5 & 2.2 & 1.3 & 4.0 \\
\hline & 35 & -0.4 & 0.6 & 1.8 & -0.4 \\
\hline & 36 & -1.1 & -1.5 & 0.0 & -0.3 \\
\hline & 37 & -1.6 & -1.6 & -2.2 & -2.3 \\
\hline & 38 & -2.3 & -2.8 & -4.0 & -3.2 \\
\hline \multirow{13}{*}{ 궁 } & 39 & 6.0 & 5.8 & 4.2 & 4.9 \\
\hline & 40 & 2.3 & 2.1 & 3.3 & 2.8 \\
\hline & 41 & -1.5 & -1.3 & -0.4 & 0.0 \\
\hline & 42 & -1.3 & -0.7 & -1.1 & -1.0 \\
\hline & 43 & -1.2 & -1.6 & -1.7 & -0.4 \\
\hline & 44 & -1.1 & -1.7 & -1.1 & -1.3 \\
\hline & 45 & -0.8 & -1.0 & -0.9 & -1.1 \\
\hline & 46 & -0.5 & -0.5 & -0.8 & -0.9 \\
\hline & 47 & -0.4 & -0.7 & -0.4 & -0.8 \\
\hline & 48 & -0.2 & -0.3 & -0.4 & -0.8 \\
\hline & 49 & -0.2 & -0.2 & -0.3 & -0.4 \\
\hline & 50 & -0.3 & -0.2 & -0.3 & -0.9 \\
\hline & 51 & -0.6 & -0.4 & -0.3 & -1.1 \\
\hline \multirow{13}{*}{$\begin{array}{l}\text { 声 } \\
\stackrel{\vec{\Xi}}{a}\end{array}$} & 52 & 0.2 & 0.7 & 0.8 & 0.3 \\
\hline & 53 & 0.0 & 0.3 & 0.2 & 0.6 \\
\hline & 54 & -0.3 & -0.1 & 0.1 & -0.2 \\
\hline & 55 & -0.2 & -0.2 & -0.1 & -0.3 \\
\hline & 56 & -0.2 & -0.2 & -0.2 & -0.6 \\
\hline & 57 & 0.0 & -0.2 & -0.2 & 0.3 \\
\hline & 58 & -0.2 & -0.1 & -0.1 & -0.5 \\
\hline & 59 & -0.1 & -0.1 & -0.1 & -0.3 \\
\hline & 60 & 0.0 & 0.0 & -0.1 & -0.2 \\
\hline & 61 & 0.0 & -0.1 & -0.1 & 0.0 \\
\hline & 62 & 0.0 & 0.0 & 0.0 & -0.1 \\
\hline & 63 & 0.0 & 0.0 & 0.0 & 0.0 \\
\hline & 64 & 0.0 & 0.0 & 0.0 & 0.0 \\
\hline
\end{tabular}


Figure SI1: Point Distribution for All New Construction with Kernel Density Curve, lowest / highest score possibility dropped

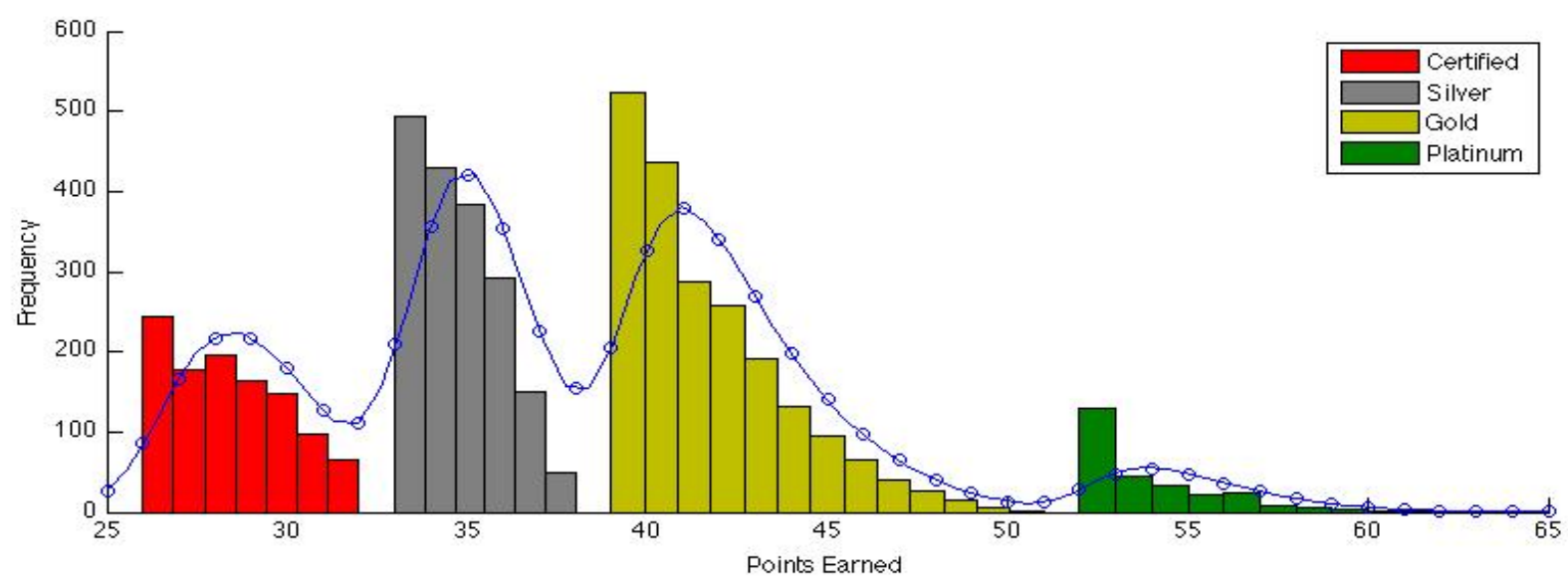

Figure SI2: Point Distribution for All For Profit Construction with Kernel Density Curve, two lowest / highest score possibilities dropped

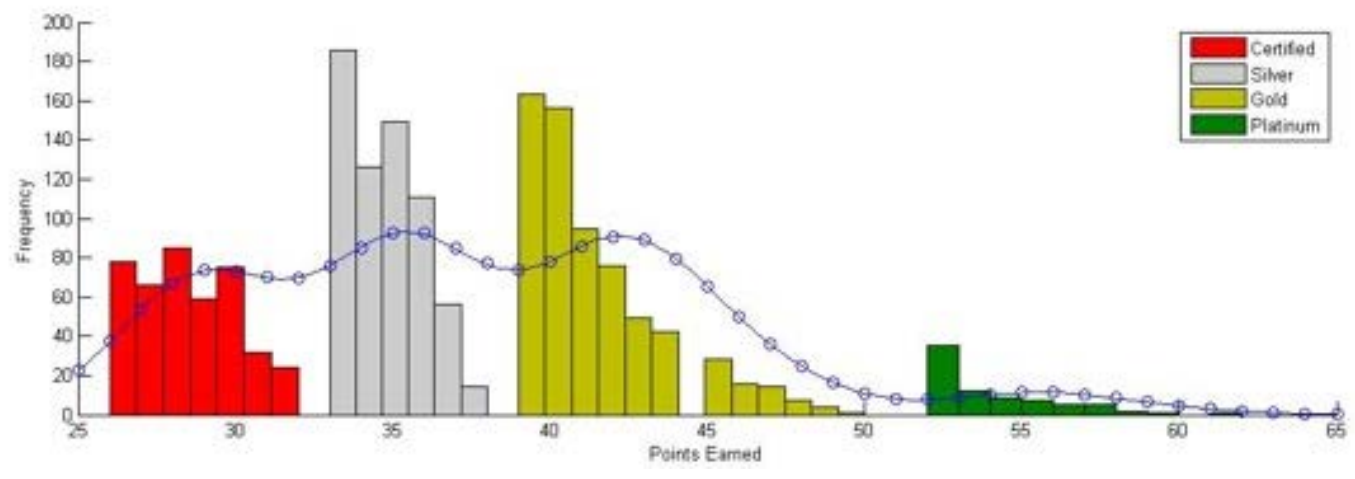

Figure SI3: Point Distribution for Government Construction with Kernel Density Curve, two lowest / highest score possibilities dropped 


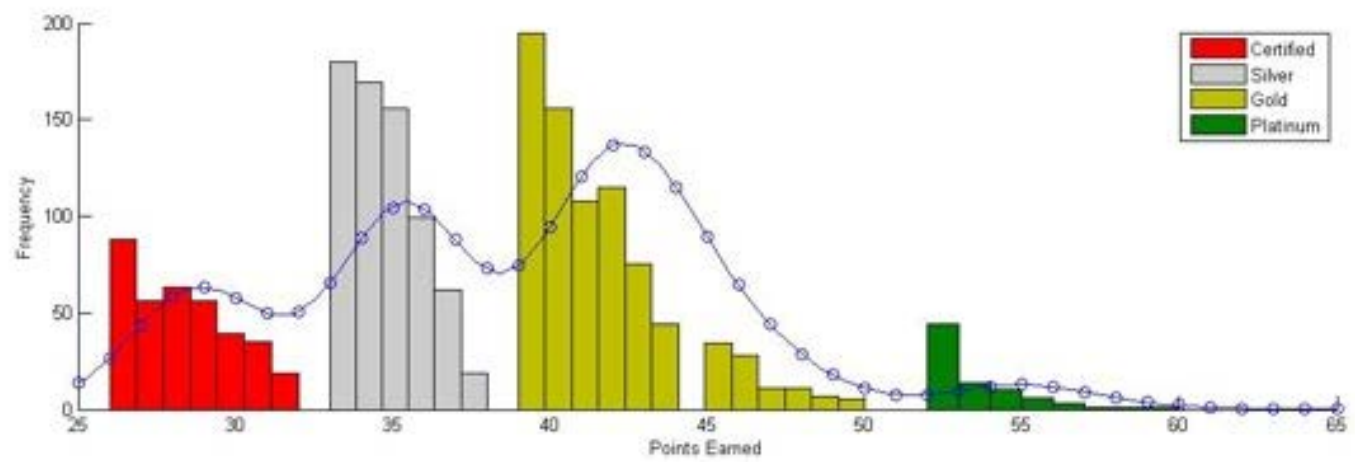

Figure SI4: Point Distribution for Government with Kernel Density Curve, 1 dropped score

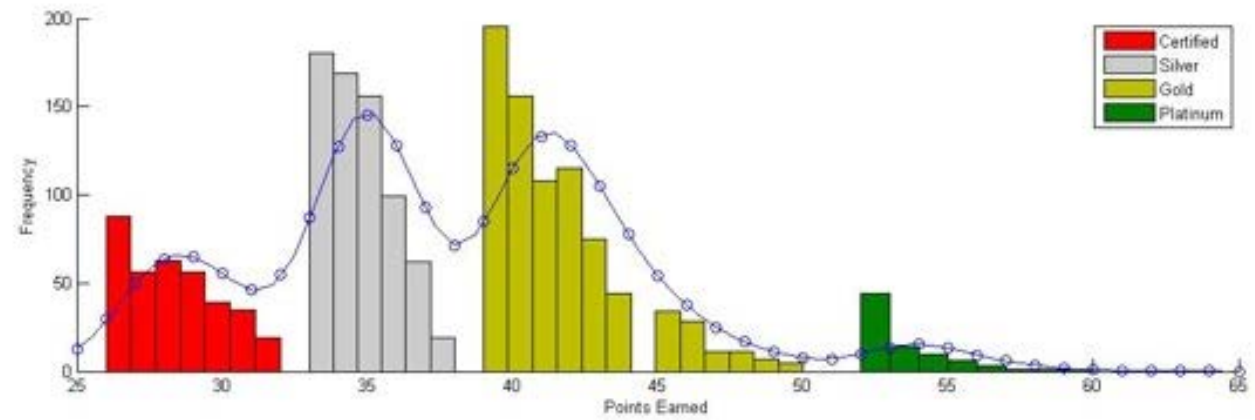

Figure SI5: Point Distribution for For-Profit with Kernel Density Curve, 1 dropped score

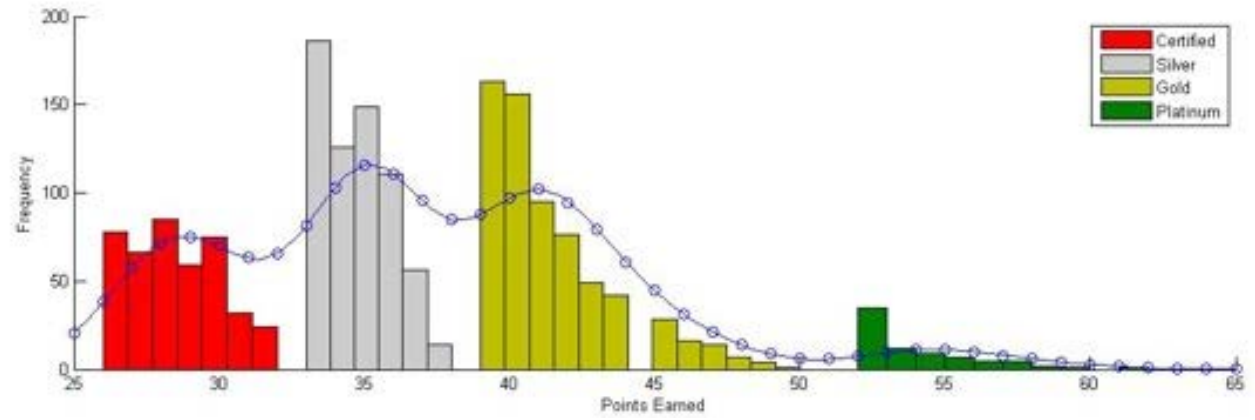


Figure SI6: Point Distribution for Non-Profit with Kernel Density Curve, 1 dropped score

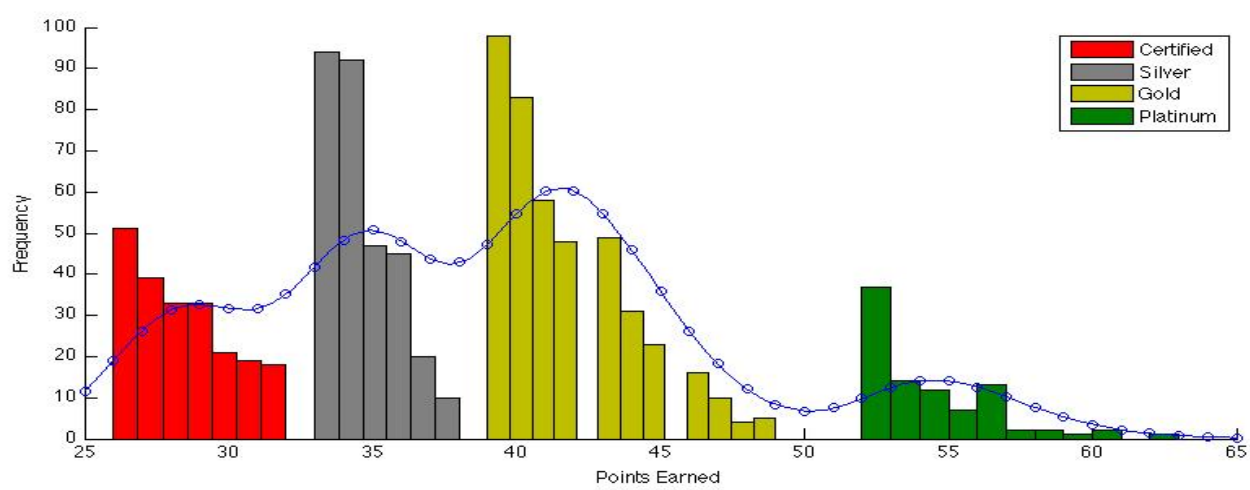

Figure SI7: Point Distribution for Non-Profit with Kernel Density Curve, two lowest / highest score possibilities dropped

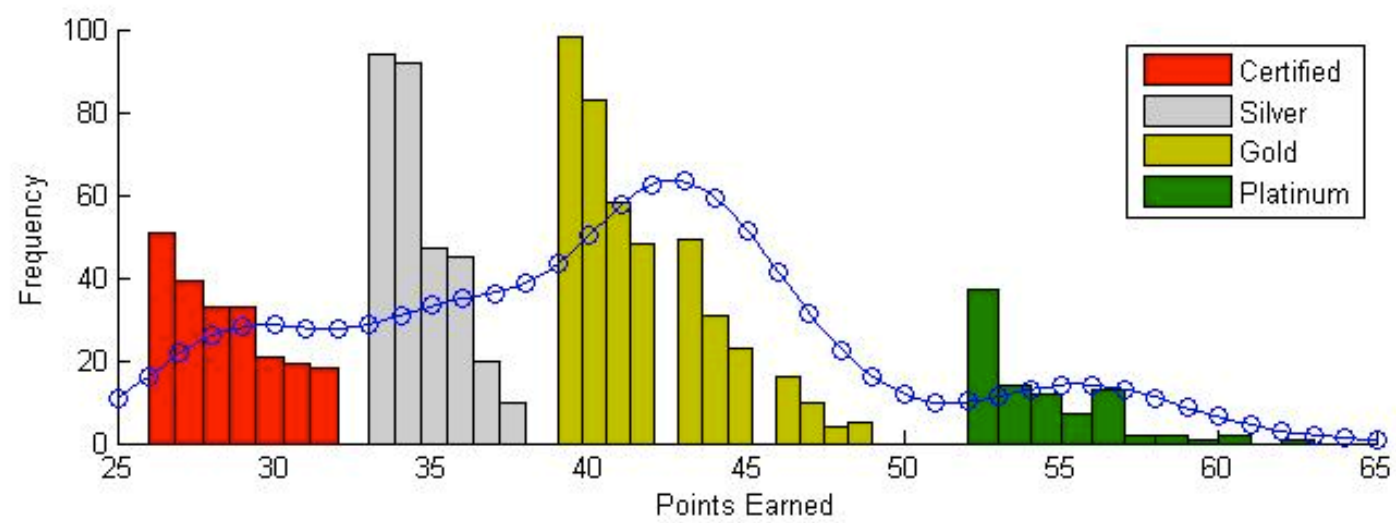

